\title{
A Damage Scenario for the 2012 Northern Italy Earthquakes and Estimation of the Economic Losses to Residential Buildings
}

\author{
Fabrizio Meroni ${ }^{1} \cdot$ Thea Squarcina $^{1} \cdot$ Vera Pessina $^{1} \cdot$ Mario Locati $^{1}$ • \\ Marco Modica $^{2} \cdot$ Roberto Zoboli $^{2}$
}

Published online: 25 September 2017

(C) The Author(s) 2017. This article is an open access publication

\begin{abstract}
In May 2012 a seismic sequence occurred in Northern Italy that was characterized by two main shocks with a magnitude range between 5.5 and 6 . These shocks represent a good case study by which to quantify the monetary losses caused by a moderate earthquake in a densely populated and economically well-developed area. The loss estimation accounts for damage to residential buildings, and considers the full effect of all the seismic aftershock events that lasted for nearly a month. The building damage estimation is based on the European Macroseismic Scale (EMS-98) definitions, which depict the effects of an earthquake on built-up areas in terms of observed intensities. Input data sources are the residential building census provided by Istituto Nazionale di Statistica-the Italian National Institute of Statistics (ISTAT) and the official market value of real estate assets, obtained from the Osservatorio del Mercato Immobiliare-the Real Estate Market Observatory (OMI). These data make it possible to quantify the economic losses due to earthquakes, an economic indicator updated yearly. The proposed multidisciplinary method takes advantage of seismic, engineering, and economic data sets, and is able to provide a reasonable after the event losses scenario. Data are not gathered for each single building and the intensity values are not a simple hazard indicator, but, notwithstanding its coarseness, this method ensures both robust and reproducible results. As the local property value is available
\end{abstract}

Fabrizio Meroni

fabrizio.meroni@ingv.it

1 Istituto Nazionale di Geofisica e Vulcanologia (INGV), Sezione di Milano, Via Bassini 15, Milan, Italy

2 Istituto di Ricerca sulla Crescita Economica Sostenibile (IRCrES), Via Corti, 12, 20131 Milan, Italy throughout the Italian territory, the present loss assessment can be effortlessly repeated for any area, and may be quickly reproduced in case of future events, or used for predictive economic estimations.

Keywords Earthquake damage $\cdot$ Economic losses · EMS-98 intensity · Northern Italy · 20 May 2012 earthquake

\section{Introduction}

Seismic risk awareness has considerably increased in Italy, especially after the latest earthquakes (2009, 2012, and 2016) that have caused tragic human and economic losses. Due to the growing concentration of economic assets and people located in urban areas that are exposed to seismic hazard, the risk and the related economic loss caused by their occurrence are becoming increasingly significant.

The demand for a detailed and fully documented seismic risk analysis is increasing from both civil protection agencies and insurance companies. These entities are looking for more accurate data on seismic hazard exposure and the consequent response to the damage of the existing buildings. Local administrators also urgently require the results of seismic risk analysis, especially in those Italian regions of medium to low seismicity and high residential and productive density. In these locations, the risk level is more influenced by exposure and vulnerability factors (Riedel et al. 2015), as in the case of the Emilia-Romagna Region.

The 2012 Emilia earthquake sequence, despite only moderate magnitude, was characterized by a series of events that generated extensive damage in a densely inhabited area, one of the richest Italian industrial districts. 
Severe structural damage to approximately 500 factories in the Emilia district was reported (Liberatore et al. 2013). Many precast concrete industrial structures were heavily damaged, and up to 7000 employees lost their jobs because of the direct or indirect effects of this disaster. Overall, the sequence resulted in 27 victims, significant damage to public and private structures, and damage to historical heritage such as churches, towers, castles, and palaces (Mucciarelli and Liberatore 2014). The National Council of Engineers estimated overall losses of about 13 billion Euro based on the funding requested from the Italian government for reconstruction (Centro studi 2014). These figures refer to: (1) restoration of residential and public buildings; (2) damage to infrastructure; (3) damage to historical and artistic heritage; and (4) impact on productive activities. A similar estimated loss was confirmed by an independent source (Bevere et al. 2015) without accounting for the secondary losses due to the interruption of industrial production.

Losses reflect the vulnerability to earthquakes of the urbanized setting. Most of the buildings were not designed according to any seismic resistance standard because the area was not seismically classified under a national law when the regional administrators noted the suggested national classification proposed in 2003 and applied it to new construction (OPCM 3274 2003). During a long transitional period in which the new standards were supposed to be introduced, administrators did not enforce the adoption of appropriate technical standards and for this reason the number of residential buildings constructed with appropriate seismic design cannot be easily estimated. The percentage of seismic designed buildings can be assessed only approximately in 66 municipalities previously "not classified" and considered as part of the medium-low seismic risk zone in 2003. On average, the percentage of buildings designed for seismic-resistance in the study area is approximately $4 \%$ of the total number of existing residential buildings. There are some differences between provinces, which range from $2.5 \%$ for the municipalities of Mantova Province to $6 \%$ for those of Bologna. In theory, these estimated values could be even smaller, because the new release of the national seismic building code (Norme Tecniche per le Costruzioni 2008) was only enforced in the Emilia-Romagna Region after 2009. Late approval of dedicated laws explains the substantial absence of any seismic damage reduction measures applied to the buildings hit by the 2012 earthquake, especially residential houses.

The scientific literature presents various methodologies for generating a damage scenario for built-up areas impacted by an earthquake (Erdik et al. 2010), each method combines variables in different ways. Among them, there are methods that use macroseismic intensity data as the major input, which initially were developed during a series of national research projects aimed at generating earthquake risk scenarios (Giovinazzi and Lagomarsino 2004; Bernardini et al. 2008; Meroni et al. 2008a, b). These methods differ in their definition of building vulnerability, but all are based on the damage definitions of the European Macroseismic Scale (EMS-98) developed by Grünthal (1998). Thanks to their ease of use, robustness, and flexibility, these methods have been widely circulated at a European level (Mouroux and Le Brun 2006; Spence 2007; Lantada et al. 2010; Zonno et al. 2010; Syner-G Project 2012; UPStrat-MAFA 2012).

Methods based on macroseismic intensity data provide statistically reliable results only when applied to large areas and to a large buildings stock. These methods have to cope with the extreme variability of the response of existing buildings to seismic loads, often influenced by site-specific effects. Another important consideration is the limits in vulnerability assessment due to the lack of satisfactory information on construction materials and techniques (Riedel et al. 2015). In order to handle the lack of calibration of these empirical methods to the highest damage degree, a validation is presented by Pessina et al. (2014) in the case of the historic center of L'Aquila, which was heavily damaged by an earthquake in 2009. A detailed case study was undertaken in L'Aquila because vulnerability and damage data exists for each building in the municipality.

The damage assessment method presented in this article classifies the housing stock into six classes of increasing vulnerability, from $\mathrm{A}$ to $\mathrm{F}$, on the basis of the main structural and nonstructural components (cladding, roofing, and decorative elements, for instance) of the building. Our method also estimates the damage distribution conditioned to the seismic intensity levels, defining five degrees of damage (from D1 to D5). The method estimates the damage occurred to residential buildings that is based on the use of Istituto Nazionale di Statistica-the Italian National Institute of Statistics (ISTAT) - census data and on the macroseismic intensity assigned to each inhabited locality struck by the earthquake. Once the intensity is known, it is possible to estimate the damage level by evaluating a priori the building vulnerability using ISTAT (1991) data. It is possible to transpose the damage degrees into levels of reduction of functionality (total or partial) and collapse (partial or total), and then associate an economic value that quantifies the loss.

\section{Macroseismic Data of the May 2012 Emilia Earthquake}

On 20 May 2012, an earthquake of magnitude $M_{\mathrm{L}} 5.9\left(M_{\mathrm{w}}\right.$ 5.86) hit the town of Finale Emilia and the surrounding localities of the Po Valley in northern Italy, about $30 \mathrm{~km}$ 
west of the city of Ferrara (Fig. 1). Only nine days later, a second event of magnitude $M_{\mathrm{L}} 5.8\left(M_{\mathrm{w}} 5.66\right)$ occurred about $20 \mathrm{~km}$ east of the previous one (Scognamiglio et al. 2012). The entire seismic sequence consisted of more than 2200 shocks that struck an area of about $50 \times 15 \mathrm{~km}^{2}$, extended in west to east direction, with only six events of magnitude $M_{\mathrm{w}} \geq 5$.

The sequence matches the well-known tectonic settings of the area, characterized by a northward verging active thrust front buried under thick alluvial deposits of the Po River plain, with little evidence at the surface (Burrato et al. 2012). Historical reports for this area record few events (Rovida et al. 2016) with moderate magnitude around $M_{\mathrm{w}} 5.5$, among which the Ferrara (1570) and the Argenta (1624) quakes represent typical cases. But recent studies suggest that the historical seismicity record of the area is far from complete (Castelli et al. 2012).
Right after the first damaging event of 20 May, two distinct macroseismic surveys were performed. These data collection efforts covered a total number of 196 localities, distributed over 88 municipalities (Fig. 1c). During the early emergency phase, 187 localities were surveyed based on the MCS (Mercalli Cancani Sieberg) scale (Sieberg 1930), which is suitable for a faster attribution of intensities. The maximum assessed MCS intensity was VII-VIII (Galli et al. 2012). The EMS-98 macroseismic scale (Grünthal 1998) was used by another group of experts to assess the intensity of 87 localities, and obtained a maximum intensity of VIII (Tertulliani et al. 2012). The intensity estimation that employed the EMS-98 scale takes longer than its MCS counterpart, because the EMS-98 scale requires a more detailed survey of the entire locality. So the area surveyed with the EMS-98 scale was restricted to those localities closer to the epicentral area, and resulted in only a few points with low intensity estimates. Given the
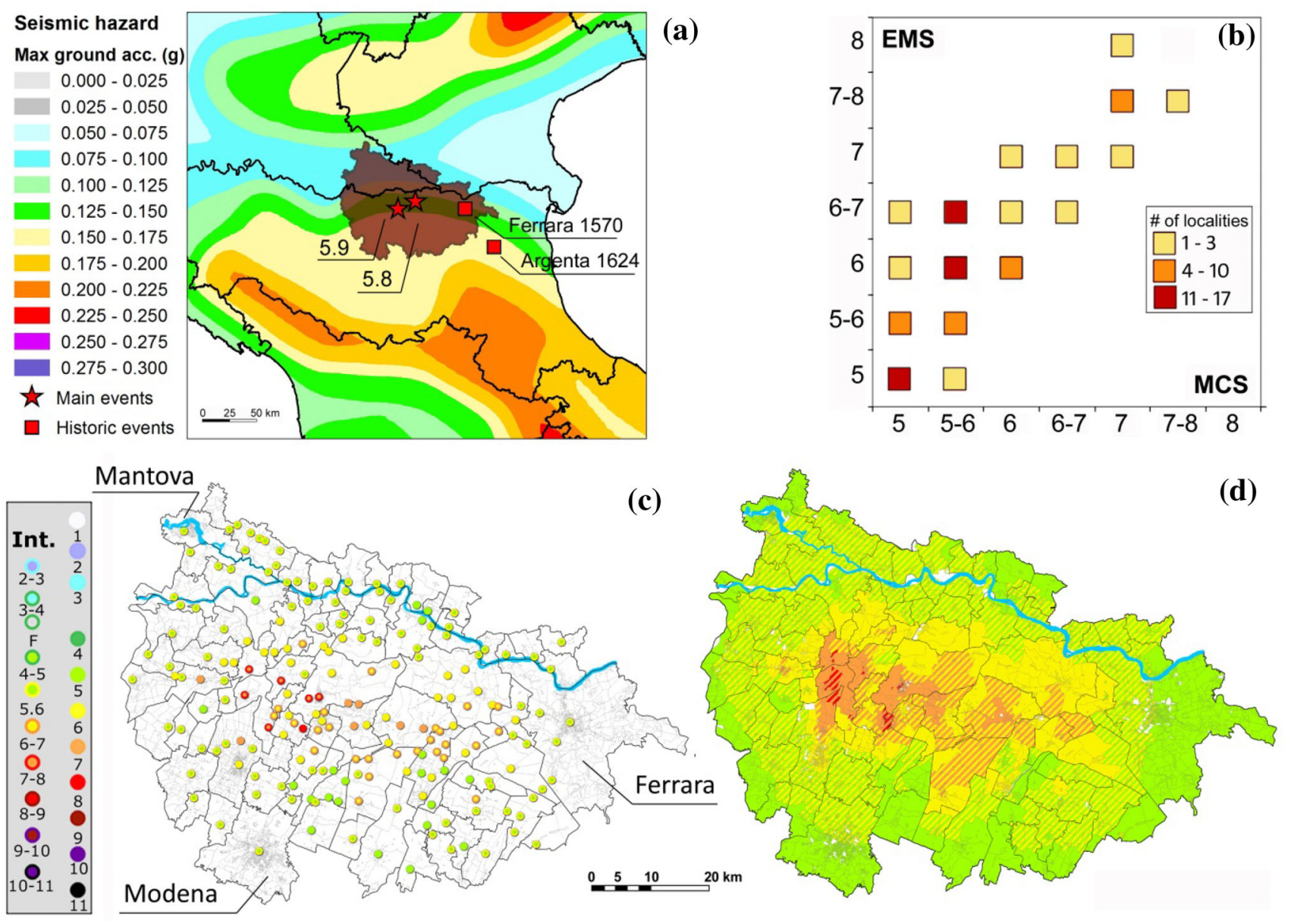

Fig. 1 Investigated area and related seismic data. a The seismic hazard map of northern Italy with regions (black boundaries) and the study area (brown shape). b Comparison between EMS-98 and MCS (Mercalli Cancani Sieberg) macroseismic observations; results are represented in three classes according to the number of the surveyed localities. c Map of 196 macroseismic observations by integrating the EMS-98 with the MCS observations. d Map of EMS-98 intensity scenario obtained by the data interpolation. The blue line represents the Po River. Source Rovida et al. (2016), Gruppo di Lavoro MPS (2004) 
Table 1 Typological parameters of buildings, according to the 1991 Italian National Institute of Statistics census data. Source ISTAT (1991)

\begin{tabular}{lllll}
\hline Structural typology & Building age & Number of floors & Isolated or contiguous & Maintenance status \\
\hline Masonry & Before 1919 & & \\
Reinforced concrete & From 1919 to 1945 & 1 or 2 & Isolated & Good \\
Soft first storey building & From 1946 to 1960 & $3-5$ & Contiguous & Bad \\
& From 1961 to 1971 & & \\
Other typology & From 1972 to 1981 & 6 or more & & \\
No info & After 1981 & & \\
\hline
\end{tabular}

complexity of the seismic sequence, the collection of intensity data considers the overlapped effects of damage due to all events (Tertulliani et al. 2012).

Since the proposed damage estimation method is based on the EMS-98 scale definitions, we tried to use all the available intensities assessed in the field independently from the adopted scale in order to improve the reliability of the shaking scenario. The relationship between the two different intensity scales had to be verified. Musson et al. (2010) suggest that an estimated EMS-98 and MCS intensity can be considered equal, but an in-depth analysis of the available intensity data for the 2012 earthquake shows a different trend. We compared the MCS and EMS98 intensity values in the 78 localities surveyed by both groups (Fig. 1b). The differences between EMS-98 and MCS values are positive ( 45 cases) or null (30 cases), they are slightly dependent on the level of intensity and are about 0.4 on average.

Congruent with the observed trend, the 87 intensities with the EMS-98 estimations were integrated with 109 additional MCS intensities increased by half a degree, which resulted in a total number of 196 macroseismic observations (Fig. 1c). The extra uncertainty added by this procedure outweighs the disadvantage of an otherwise extremely partial scenario that only considered a small epicentral area. The integrated MCS points are characterized by low intensities ( 87 points with intensity $\mathrm{V}$ and 17 with intensity V-VI). The intensity increase of half a degree is conservative and it accounts for low damage level on a wide area.

Subsequently these 196 intensity points were interpolated by applying the Natural Neighbor method, which produces a reliable intensity scenario for all localities (Fig. 1d). Among the array of interpolation algorithms available, the Natural Neighbor method (Sambridge et al. 1995) was selected because it is ranked among one of the most conservative solutions, as reported in various studies (Bater and Coops 2009; Montealegre et al. 2015). The Natural Neighbor method is a useful way to interpolate reference points by applying to them weights based on proportionate areas that are defined by the surrounding points (Voronoi polygons). The interpolated surface passes through the input samples and it is smoothed everywhere except that in the locations of the input samples. Consequently, the originally assessed intensity values are fully preserved. In addition to its computational efficiency, this method also works well with the irregularly distributed data that characterizes our case study.

\section{The Vulnerability of the Residential Buildings}

Census data are important for assessing residential building vulnerability over large areas. The Italian National Institute of Statistics (ISTAT) periodically conducts a census of dwellings and provides a set of information on housing that is useful for seismic damage assessment. Census data are available for the entire country, and these data allow a reliable estimate of the total number of buildings and their corresponding volume; a rough classification in terms of age and some typological parameters is provided as well.

ISTAT data on residential buildings are provided at census tract resolution, a subdivision of the municipality. When data on census tracts are disaggregated, it is possible to correlate the information. Buildings are described by multiple characteristics: structural typology, date of construction (or renovation), number of floors, building position in the block, state of repair, and quality of maintenance (Table 1). By correlation of these statistical variables, it is possible to quantify associated features of the buildings (that is, how many buildings with a specific structural typology, for a given building age and number of floors, with certain aggregation status and maintenance level are in each census tract).

Vulnerability is evaluated using the approach proposed by Bernardini et al. (2008), which defines a score for homogeneous groups of buildings. The classification procedure is consistent with a vulnerability assessment (Meroni et al. 2000) calibrated on more than 28,000 detailed GNDT (Gruppo Nazionale per la Difesa dai Terremoti- 
Table 2 Elements for the vulnerability assessment method based on the 1991 ISTAT data. Source Bernardini et al. (2008)

(a) Parameters for the classification of typological structures

\begin{tabular}{|c|c|c|c|c|c|}
\hline$k$ (type) & $\begin{array}{l}1 \\
\text { Soft storey }\end{array}$ & $\begin{array}{l}2 \\
\text { R.C. }\end{array}$ & $\begin{array}{l}3 \\
\text { Masonry }\end{array}$ & $\begin{array}{l}4 \\
\text { Other }\end{array}$ & $\begin{array}{l}5 \\
\text { Unknown }\end{array}$ \\
\hline$I_{\mathrm{v}} 11(k)$ & 50 & 45 & 60 & 55 & 52 \\
\hline$D e l t a \_i(k)$ & -20 & -20 & -25 & -20 & -22 \\
\hline$D e l t a \_j(k)$ & -10 & -15 & -15 & -15 & -15 \\
\hline Manut $(k)$ & -10 & -10 & -10 & -10 & -10 \\
\hline Classif (k) & -10 & -20 & -10 & -10 & -15 \\
\hline
\end{tabular}

(b) Parameters for the classifications of age of construction and typological factors

\begin{tabular}{lllll}
\hline$i$ & Range of age of constructions & $j$ & \multicolumn{2}{l}{ Typological factors } \\
\cline { 3 - 5 } & & & Aggregations & $3(>4)$ \\
1 & $<1919$ & 1 & 2 (yes) & $2(3-4)$ \\
2 & $1919-1945$ & 2 & $2($ yes $)$ & $3(>4)$ \\
3 & $1946-1961$ & 3 & 1 (no) & $2(1-2)$ \\
4 & $1962-1971$ & 4 & $2($ yes $)$ & $1(3-4)$ \\
5 & $1972-1981$ & 5 & 1 (no) & $1(1-2)$ \\
5,4 & $1982-1984$ & 6 & &
\end{tabular}

(c) Criterion of classification in the EMS-98 vulnerability classes

\begin{tabular}{lllllll}
\hline EMS-98 class & A & B & C & D & E \\
\hline$I_{\mathrm{V}}$ (mean) & $50<I_{\mathrm{V}}$ & $30<I_{\mathrm{V}} \leq 50$ & $10<I_{\mathrm{V}} \leq 30$ & $-10<I_{\mathrm{V}} \leq 10$ & $-30<I_{\mathrm{V}} \leq-10$ & $I_{\mathrm{V}} \leq-30$
\end{tabular}

National Group for the Defence Against Earthquakes) buildings vulnerability forms (Benedetti and Petrini 1984) collected from all over Italy. In our study, an average GNDT vulnerability index was evaluated for homogenous groups of buildings on the basis of cross-correlated ISTAT parameters.

In Bernardini et al.'s (2008) approach, the typological parameters, derived from ISTAT data (for example, age, number of floors, and structural context), provide a vulnerability index according to the following relationship:

$$
\begin{aligned}
I_{\mathrm{v}}(i, j, k)= & I_{\mathrm{v}}^{1}(k)+\text { Delta_i }(k) *(i-1) / 5+\operatorname{Delta}_{-} j(k) \\
& *(j-1) / 5+\operatorname{Manut}(k)+\text { Classif }(k)
\end{aligned}
$$

For a given $k$ structural typology, the factors Delta_ $i$ and Delta $\_j$ (Table 2a) refer respectively to the $i$ ranges of the construction age (or total retrofitting) of the buildings and to the $j$ typological factors shown in Table $2 \mathrm{~b}$. The factors Manut and Classif account for the state of building maintenance and the year of seismic classification of the municipality. The last parameter was not applied in the present analysis because the seismic norms in this area were only enforced after 2009. The amount of housing built after 2009 cannot be quantified by ISTAT data.

The corresponding EMS-98 vulnerability class is determined according to the range of the vulnerability score, as shown in Table 2c (Bernardini et al. 2008). Vulnerability classes range from A (the weakest buildings, having the highest indices) to $\mathrm{F}$ (the most resistant ones, with the lowest scores). In general, masonry buildings, which have a vulnerability index between 0 and 60 , belong to classes from A to D; reinforced concrete buildings have an index between -20 and 45 (classes B-E); soft first storey buildings have an index between 0 and 50 (classes B-D).

Despite the fact that recent studies (for example, Riedel et al. 2014) suggest a probabilistic assessment of vulnerability in order to account for uncertainties in the class assignment, we adopted the vulnerability classification proposed in Bernardini et al. (2008) in the expectation that a deterministic approach calibrated on a large amount of Italian building data can be sufficiently reliable.

The 1991 census (ISTAT 1991) was taken as the starting point, since it provides disaggregated data at census tract resolution. The latest censuses conducted in 2001 and 2011 only deliver aggregated data publicly for the residential building stock, which makes it impossible to correlate information at municipal level. The latest censuses comply with a strict national law on confidentiality of information, enforced beginning in 1996, which prohibits the public delivery of data that may expose sensitive personal 
information. This limitation does not allow an intersection of the building typological characteristics, which is a basic and fundamental step for applying the method of seismic vulnerability evaluation adopted in this research.

For this reason, a different approach had to be implemented for the vulnerability assessment of housing built after 1991. By performing our analysis at a municipal scale, which is the smallest administrative area where a good level of accuracy is assured, we found a compromise solution. As a first step, the 1991 census data was compared to both the 2001 and 2011 censuses, in order to quantify the variations in building typological characteristics over the last 20 years and to understand how much the pre 1991 data might fit the existing situation. In the 88 municipalities considered, the number of inhabitants increased by more than 100,000 units and the built-up environment increased approximately by $19 \%$ between 1991 and 2011. Figure 2a shows an overview of housing stock growth, expressed in terms of a percentage for each province; the most evident changes are found in Modena and Ferrara Provinces, which increased by 34 and $21 \%$ respectively.

A new EMS-98 vulnerability distribution is evaluated for housing built after 1991, matching the unaggregated variables of the 2011 census available at the provincial level. Because the unaggregated building characteristics available are limited to the structural typology, age of construction, and quality of maintenance, the vulnerability assignment method proposed by Bernardini et al. (2008) was only partially adopted. To improve the reliability of the classification, the other missing parameters (number of floors and position in the block) were analyzed by assigning both the minimum and the maximum score admitted in the Bernardini et al. (2008) method. In order to ensure the greatest safety, the final classification was performed by investigating all the possible combinations

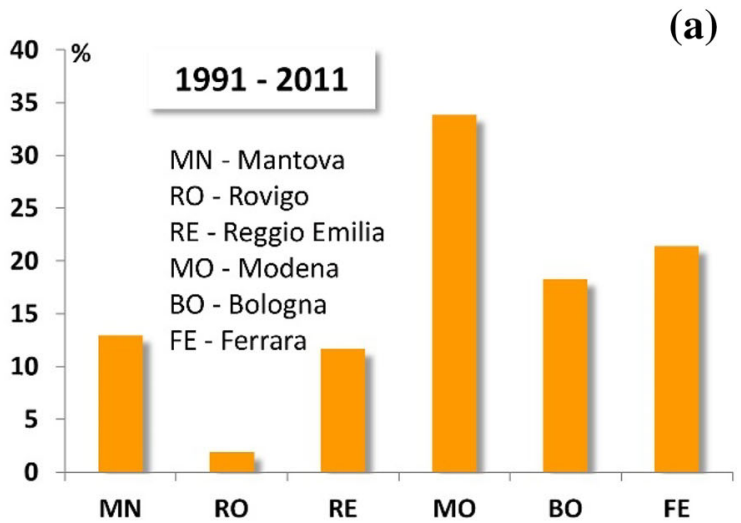

Fig. 2 Variation of building consistency between 1991 and 2011. a Percentage increase of the building stock in the last two decades related to 88 municipalities hit by the May 2012 earthquake sequence, grouped into provincial administrations. b Vulnerability distribution among these scores and assuming the higher vulnerability class associated.

To quantify the amount of housing stock growth in each municipality the trend of the census variable-housing surface occupied by at least one inhabitant—was evaluated over the last 20 years. We assumed that the variation of the building stock is ruled by the following conditions: (1) in case of a positive variation, we assumed that the new buildings follow the vulnerability distribution assessed at the province level; (2) those municipalities with a negative trend in their building stock would most likely have eliminated buildings in the worst conditions. Finally, a vulnerability distribution was obtained, projected on the data of the 2011 ISTAT census.

This vulnerability distribution cannot be easily implemented at the census tract level because the quality and resolution of the census tract boundaries, published by ISTAT, have drastically changed at every census release. Taking into account 20 years of administrative evolution, the researcher has to consider that some municipalities have merged, other census tracts were moved to neighboring municipalities, and some municipalities migrated to a neighboring province.

Figure $2 b$ shows the estimated distribution of building vulnerability classes based on ISTAT 1991 data and its updated values to year 2011. The updated distribution of vulnerability shows an increase in the lower vulnerability classes (C and $\mathrm{D})$, and a slight decrease in the most vulnerable classes (A and B). This overall pattern demonstrates an expected decrease in building vulnerability in the last 20 years in the study area owing to a better construction quality of the newer buildings.

The vulnerability distribution of building stock in the study area is mapped in Fig. 3 for each EMS-98 class: the area under investigation is characterized by the predominance of buildings in vulnerability categories $\mathrm{C}(62 \%)$ and

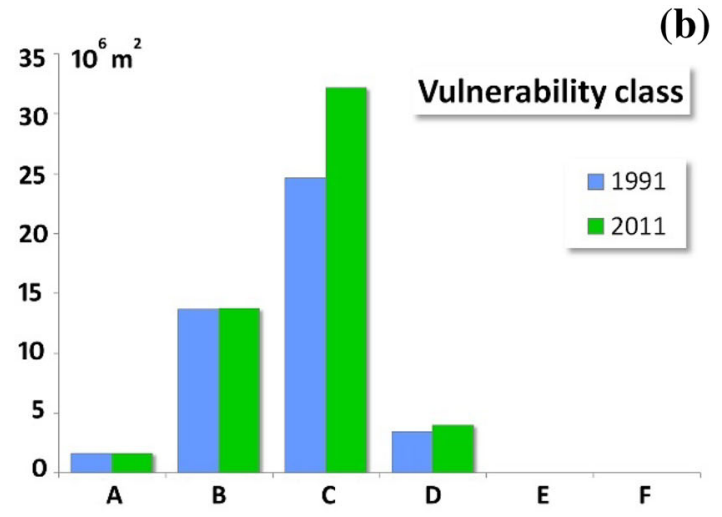

of residential buildings into classes A to $\mathrm{F}$. The built areas (million $\mathrm{m}^{2}$ ) refer to the 1991 Italian National Institute of Statistics (ISTAT) census data and their updating in the year 2011 

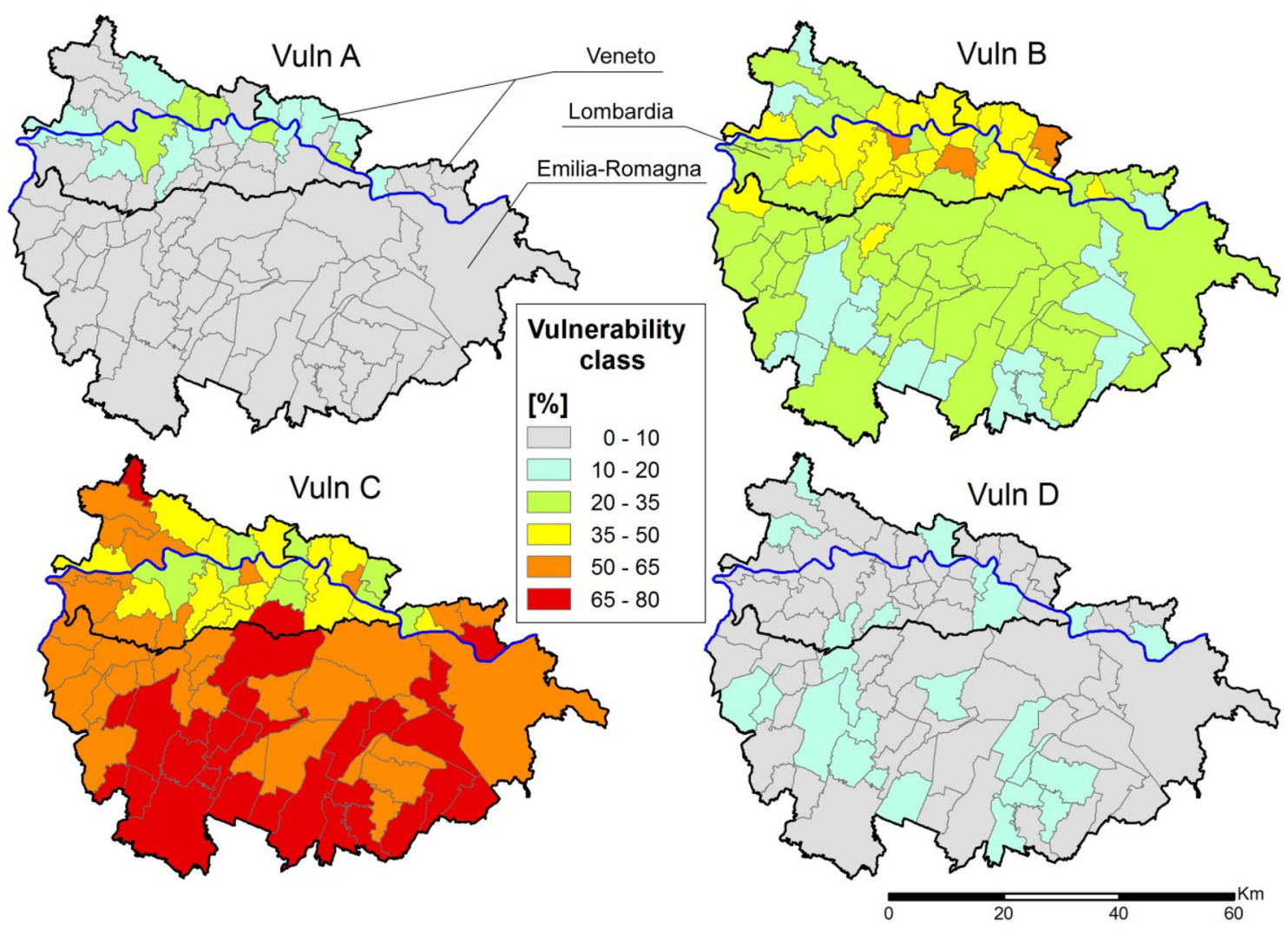

Fig. 3 Vulnerability distribution of residential buildings into the classes A-D (buildings in classes $\mathrm{E}$ and $\mathrm{F}$ are not present). The built area $\left(\right.$ in $\mathrm{m}^{2}$ ) refers to the data updated to the 2011 ISTAT census. The

B $(27 \%)$, with fewer buildings in class D (8\%) and A $(3 \%)$. Overall, the vulnerability levels of buildings were lower in the Emilia-Romagna Region than those in Lombardia and Veneto Regions, where the extremely fertile territory, crossed by the Po River, is characterized by rural, wider dispersed, and poorer settlements (Fig. 3).

\section{The Damage Estimation Based on Macroseismic Data Interpretation}

Methods for building damage assessment based on definitions contained in the EMS-98 scale classify residential buildings into 6 vulnerability classes (A-F), and evaluate their damage distribution in five classes (D1-D5: negligible, moderate, substantial to heavy, very heavy damage, and destruction), which accounts for the damage level of both the main structural and nonstructural components.

The EMS-98 scale adopts qualitative ratings to evaluate the frequencies of buildings with different degrees of damage, for each vulnerability class and for each macroseismic intensity (V-XII) found in Table 3a. For instance, the scale defines that intensity degree VI has occurred when "damage of grade 1 is sustained by many buildings percentage values are shown at municipal scale, darker lines represent regional boundaries. The blue line represents the Po River

of vulnerability class $\mathrm{A}$ and $\mathrm{B}$; a few of class $\mathrm{A}$ and $\mathrm{B}$ suffer damage of grade 2; a few of class $C$ suffer damage of grade 1" (Grünthal 1998, p. 18).

According to these methods, it is possible to define the damage probability matrices implicitly encoded within the EMS-98 scale. The damage scale also could be described through the interaction between the vulnerability classes and the assessed intensity. The qualitative ratings are selfexplanatory terms (for example, few, many, most) that can be expressed in fuzzy mode into numerical values of probability (damage probability matrix) as formalized by several authors (Lagomarsino and Giovinazzi 2006; Bernardini et al. 2007).

In the EMS-98 scale it is not possible to assign a precise value to damage probability because the self-explanatory terms are defined as a range of values and because some classes of vulnerability and intensity are characterized by at least two levels of damage. Following the numerical approach based on a fuzzy set theory by Bernardini et al. (2007), it is possible to extrapolate a complete description of the damage distribution by making a reasonable linguistic completion to the definitions provided by the scale. The authors introduce five more adjectives (Nearly None, Few, Many, Most, and Nearly All) and quantify them with 
Table 3 Different versions of damage probability matrices based on the EMS-98 scale

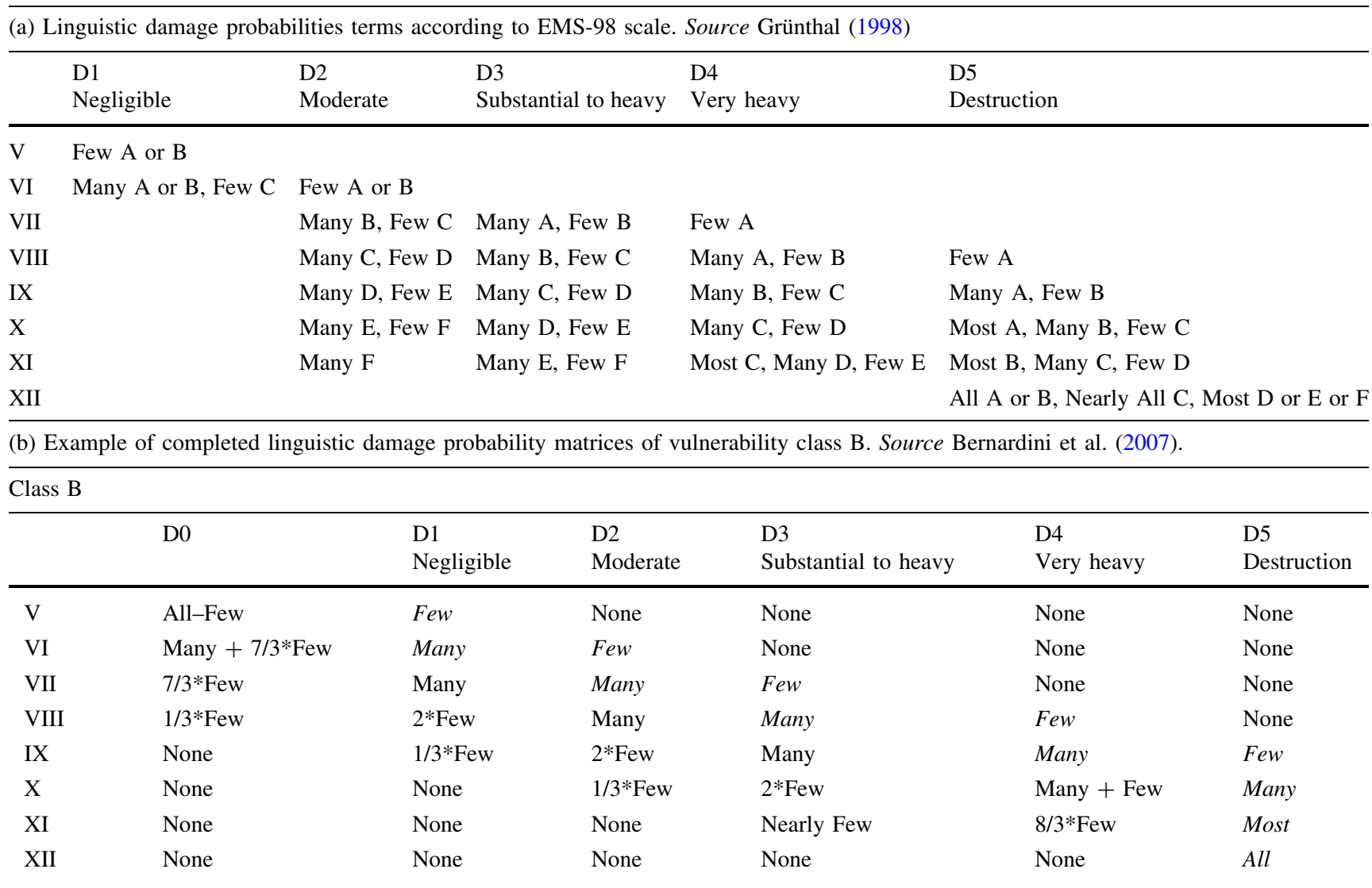

(c) Damage probability matrix for class B expressed in numerical values. Source Meroni et al. (2016)

\begin{tabular}{|c|c|c|c|c|c|c|}
\hline \multicolumn{7}{|c|}{ Class B } \\
\hline & D0 & D1 & D2 & D3 & D4 & D5 \\
\hline V & 0.91 & 0.09 & 0 & 0 & 0 & 0 \\
\hline VI & 0.56 & 0.35 & 0.09 & 0 & 0 & 0 \\
\hline VII & 0.21 & 0.35 & 0.35 & 0.09 & 0 & 0 \\
\hline VIII & 0.03 & 0.18 & 0.35 & 0.35 & 0.09 & 0 \\
\hline IX & 0 & 0.03 & 0.18 & 0.35 & 0.35 & 0.09 \\
\hline$X$ & 0 & 0 & 0.03 & 0.18 & 0.44 & 0.35 \\
\hline XI & 0 & 0 & 0 & 0.015 & 0.24 & 0.745 \\
\hline XII & 0 & 0 & 0 & 0 & 0 & 1 \\
\hline
\end{tabular}

Italics cells indicate EMS-98 definitions. Roman cells indicate the extension according to the above described rules

the condition that the sum of the percentage for each of the membership functions for each fuzzy set is equal to 1 . To respect this condition, one more class of damage was introduced in the extended matrix that corresponds to the state of No damage (D0). The result of the linguistic completion of the EMS-98 scale is summarized in Table $3 b$.

This study adopts the numerical assumptions proposed by Bernardini et al. (2007) for the quantification of terms in the damage probability matrix (an example, for class $\mathrm{B}$, is shown in Table 3c) (Meroni et al. 2016). The distributions of the built-up area for each level of damage are illustrated in Fig. 4.

The damage distribution maps show a much-damaged central area, which was affected by both mainshocks of the 2012 earthquake on 20 and 29 May. Here, the municipalities of Mirandola, Cavezzo, Novi di Modena, Moglia, and Concordia sulla Secchia recorded the highest percentage of damage for all D1 to D5 damage levels due to seismic shaking and, probably, the occurrence of site effects. In the 

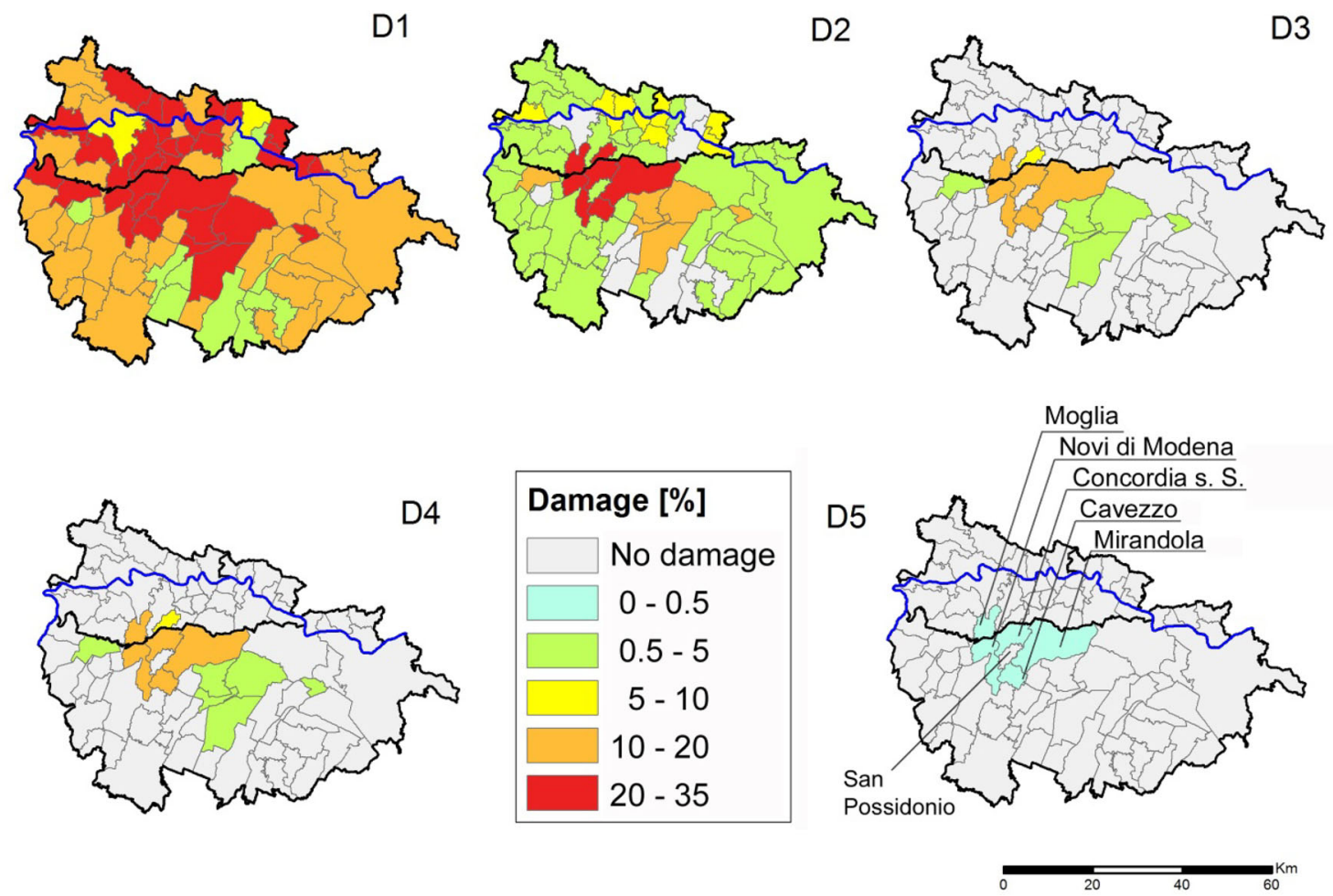

Fig. 4 Percentage distribution of damaged buildings within damage levels from D1 to D5. The blue line represents the Po River

town of San Possidonio, placed exactly in the middle of the municipalities mentioned above, the damage level is lower because of the low intensity observed.

Two outlying areas appear from the D4 level down, bordering the high damaged central zone to the west and east. Each of these areas is the closest to one of the two epicenters so, most probably, these municipalities were hit mainly by one of the two earthquakes, and their buildings have suffered a higher damage compared to other parts of the territory, but they are less affected than those areas between the two epicenters.

\section{Market Values of Residential Buildings}

In this study we develop an analysis of monetary losses due to earthquakes that relies on housing market values. Typical approaches that attempt to assess monetary losses are firmly based on reconstruction costs-those costs required to restore a building to the same physical and functional conditions as before the seismic event-for example the reports by Associazione Nazionale fra le Imprese AssicuratriciNational Association of Insurers Companies (ANIA and Guy Capenter groups 2011). Reconstruction costs do not consider the exposed real estate value, which causes a potential underestimation of the total amount of monetary losses. In fact, there is no well-recognized housing value that describes intrinsic and objective characteristics (Davis 2011; Modica et al. 2016), because these features may vary according to a series of factors that depend on evaluation goals-more precisely on the established relationship between the value of a good and the people wishing for access to that good. Moreover, the cost of (re)construction heavily depends on the building location with respect to the construction market, which is mostly uncorrelated to the real estate market (Cipollotti 2013). In the end, reconstruction costs can only partially reflect exposed real estate value and potential monetary loss. As an example, even in a case where the housing value is equal to the cost of reconstruction, the perceived risk in an area may change after a seismic event. This altered perspective can lead to a situation in which the initial housing value cannot be fully restored with the simple reconstruction costs (Murdoch et al. 1993; Naoi et al. 2009).

The housing market value, even with its well-known limits, can be adopted for evaluating the monetary losses produced by an earthquake, because such a value represents well the aggregated sum of multiple socioeconomic factors, from the perceived value of the area where the building is located up to the construction quality. The assumption of this study is that the difference in housing market value before and after a catastrophic event, such as an earthquake, reflects accurately the resulting impact on the real estate market. Therefore market value is a more 
reliable indicator of earthquake loss than is the cost of reconstruction.

Housing market values in Italy are officially released by the Observatory of the Housing Market (OMI, the Osservatorio del Mercato Immobiliare) that is part of the Italian Revenue Agency (Agenzia delle Entrate). OMI provides semiannual estimates of the maximum and minimum values of many types of buildings at a submunicipal level based on the actual trades that take place within a given time span. OMI reports 19 building categories; this article focuses on residential buildings only, since the available macroseismic data is limited to this type of built-up area. According to OMI, built-up areas are subdivided into five categories: (1) high-quality units (for example, the residential units of a building with good general characteristics and value); (2) low-quality units (for example, residential units of a building with low overall characteristics and value); (3) prestigious units (for example, residential units with overall and historical characteristics of particular value); (4) traditional units (for example, residential units showing typical architectural and/or urban characteristic of the areas in which it is located); and (5) villas (for example, residential units with superior construction quality and exclusive characteristics such as a park or a garden).

OMI data define homogenous segments of the local real estate market, subdividing the overall built-up areas into subareas, called districts, which are areas characterized by similar socioeconomic and environmental conditions. These districts are shaped by taking into account the distance from the center of the built-up area and establishing a ranking based on five levels: historical center, semicentral, outskirt, suburb, and rural areas (Osservatorio del Mercato Immobiliare 2009). In addition, OMI takes into account the average state of building maintenance in three levels: good, normal, and poor, as well as the average building type in the area.

For both maximum and minimum values, a synthetic weighted average is calculated for all OMI structure typologies, which considers that OMI data only provides the average value for each type of dwelling per district and yields no information about the number of existing buildings. The procedure adopted to obtain a monetary value for the entire district uses socioeconomic data provided by ISTAT (population, demographic variance, employment, number of family members, and so on), and makes a number of assumptions on the causal effect of socioeconomic variables on housing quality that are linked firmly to the socioeconomic literature. The study assumes that the higher the population density is in a district, the lower the quality of the houses will be (Chay and Greenstone 2005), while the higher the socioeconomic conditions are, the better the quality of the houses will be (Glaeser et al. 2005; Glaeser and Gyourko 2005). The general procedure takes the following steps to generate both maximum and minimum values:

1. Analysis of a set of 174 variables, covering demographic (population, demographic balance, ageing, and so on), economic (employment), and social (education) information, all data provided by ISTAT and related to the 1991 census; ${ }^{1}$

2. Because ISTAT data are available at the level of the census tract, it was necessary to aggregate these tracts manually to best match the shape of each OMI district;

3. Given the large number of correlated variables in the OMI data, the information is synthesized through a principal component analysis and based on four orthogonal factors (population, $f^{1}$; employment, $f^{2}$; household characteristics, $f^{3}$; education, $f^{4}$ ), which are detailed in Table 4a;

4. A weighted average value is defined according to the probability that a type of dwelling is standing in one of the five submunicipal areas (center, semicentral, outskirt, suburb, and rural) given the difference in their socioeconomic values. For this purpose, we used a probit model, a type of regression where the dependent variable can only take two values. Dummy variables are introduced also, resulting in the following probit model:

$Y_{i, j}=f^{1} \beta^{1}+f^{2} \beta^{2}+f^{3} \beta^{3}+f^{4} \beta^{4}+\varepsilon$

where $y$ is the dummy variable of the dwelling type $i$ in the area $j, f$ are the factors of the principal component analyses, and $\varepsilon$ is the error term. The dummy assumes value 1 if in the area $j$ there is the building type $i$, and 0 otherwise. By applying this method, it is possible to identify the probability that a type of residential unit is present in each submunicipal area. Results of the probit analysis are shown in Table 4b, while normalized average weights are reported in Table 4c.

5. Housing market value data prior to the earthquake are adopted (first half of 2012) to define a weighted minimum and maximum housing value per district by using the results in Table 4c. Finally, synthetic municipal housing values are defined as the simple average of the district's housing values.

Furthermore, the mean value is defined at the municipal level, and as used in this analysis, is given by the arithmetic average between minimum and maximum municipal values as described above.

The weights reported in Table $4 \mathrm{c}$ are necessary to define the weighted average local property value at the municipal level. Indeed, according to our data we have property prices defined at category level (for example, high-low

\footnotetext{
${ }^{1}$ http://www.istat.it/it/archivio/104317.
} 
Table 4 Synthetic weighted average process (intermediate steps and final output)

\begin{tabular}{lcccc}
\hline (a) Rotated principal components factor (rotation method: orthogonal varimax) & & \\
\hline Factor & Variance & Difference & Proportion & Cumulative \\
\hline Factor 1 & 24.99657 & 10.89128 & 0.5555 & 0.5555 \\
Factor 2 & 14.10528 & 12.2853 & 0.3135 & 0.8689 \\
Factor 3 & 1.81998 & 0.31861 & 0.0404 & 0.9094 \\
Factor 4 & 1.50137 & & 0.0334 & 0.9427 \\
Observations & & & 436 \\
Number of parameters & & & 174 \\
LR test $(p$ value) & & & 0.000 \\
\hline
\end{tabular}

(b) Predicted probabilities for type of buildings and sub-municipal areas according to the probit model

\begin{tabular}{|c|c|c|c|c|c|}
\hline $\begin{array}{l}\text { Sub-municipal } \\
\text { area }\end{array}$ & $\begin{array}{l}\text { (1) } \\
\text { High-quality units }\end{array}$ & $\begin{array}{l}\text { (2) } \\
\text { Low-quality units }\end{array}$ & $\begin{array}{l}\text { (3) } \\
\text { Prestigious units }\end{array}$ & $\begin{array}{l}\text { (4) } \\
\text { Traditional units }\end{array}$ & $\begin{array}{l}(5) \\
\text { Villas }\end{array}$ \\
\hline \multirow[t]{2}{*}{ Center } & $0.992 * * *$ & $0.800 * * *$ & 0.00923 & - & $0.913 * * *$ \\
\hline & $(0.00924)$ & $(0.0452)$ & $(0.0115)$ & - & $(0.0303)$ \\
\hline \multirow[t]{2}{*}{ Semi-central } & $0.908 * * *$ & $0.751 * * *$ & 0.0149 & - & $0.971 * * *$ \\
\hline & $(0.0792)$ & $(0.117)$ & $(0.0242)$ & - & $(0.0333)$ \\
\hline \multirow[t]{2}{*}{ Outskirt } & $0.890 * * *$ & $0.778 * * *$ & - & $0.0360^{*}$ & $0.862 * * *$ \\
\hline & $(0.0330)$ & $(0.0392)$ & - & $(0.0185)$ & $(0.0297)$ \\
\hline \multirow[t]{2}{*}{ Suburb } & $0.967 * * *$ & $0.691 * * *$ & - & - & $0.855^{* * *}$ \\
\hline & $(0.0174)$ & $(0.0535)$ & - & - & $(0.0346)$ \\
\hline \multirow[t]{2}{*}{ Rural } & $0.687 * * *$ & $0.867 * * *$ & - & - & $0.213 * * *$ \\
\hline & $(0.0921)$ & $(0.0482)$ & - & - & $(0.0591)$ \\
\hline Observations & 436 & 436 & 115 & 138 & - \\
\hline
\end{tabular}

(c) Normalized average weight for type of buildings and submunicipal areas

\begin{tabular}{|c|c|c|c|c|c|}
\hline $\begin{array}{l}\text { Sub-municipal } \\
\text { area }\end{array}$ & $\begin{array}{l}\text { (1) } \\
\text { High-quality units }\end{array}$ & $\begin{array}{l}\text { (2) } \\
\text { Low-quality units }\end{array}$ & $\begin{array}{l}\text { (3) } \\
\text { Prestigious units }\end{array}$ & $\begin{array}{l}\text { (4) } \\
\text { Traditional units }\end{array}$ & $\begin{array}{l}(5) \\
\text { Villas }\end{array}$ \\
\hline Center & 0.365 & 0.296 & 0.003 & - & 0.336 \\
\hline Semi-central & 0.343 & 0.284 & 0.006 & - & 0.367 \\
\hline Outskirt & 0.347 & 0.303 & - & 0.014 & 0.336 \\
\hline Suburb & 0.385 & 0.275 & - & - & 0.340 \\
\hline Rural & 0.388 & 0.491 & - & - & 0.121 \\
\hline
\end{tabular}

Standard errors in parentheses $* * * p<0.01 ; * * p<0.05 ; * p<0.1$. All predictors at their mean values

quality houses) and at submunicipal area (for example, center, suburb, and so on). The weights are then useful for the construction of the synthetic municipal value that is used in Sect. 6 for the economic loss assessment.

\section{Economic Loss Assessment}

Most of the models for the seismic loss assessment correlate the amount of building damage to a corresponding economic loss through a parameter called the cost ratio. This ratio relates building repair cost to replacement cost (ATC 1985; FEMA 2003) and represents the decreased building value due to seismic effects. Cost ratio values especially calibrated for the EMS-98 damage classes and the Euro-Mediterranean region can be found in the earthquake risk literature (Mouroux 2003; Roca et al. 2006). Cost ratio values still are widely debated, and may vary considerably depending on the way the ratio is calculated. A validation study on seismic loss assessment in Turkey (Bal et al. 2008) proposes higher cost ratio values than those typically reported in other studies. This difference is due to the observation that replacement costs are usually higher than construction costs because of the need to consider the demolition costs and debris disposal charges of heavily damaged buildings (D4 and D5). Among the values proposed in these different studies (Meroni et al. 2016), the cost ratio values selected are reported in Table 5 .

Once the damage distribution of the built-up area is known for each municipality, it is possible to calculate the 
Table 5 Adopted cost ratio values (decrease of construction value in percentage)

\begin{tabular}{lc}
\hline EMS-98 damage class & Cost ratio $(\mathrm{Cr})$ \\
\hline D1 & $5( \pm 2)$ \\
D2 & $20( \pm 5)$ \\
D3 & $45( \pm 5)$ \\
D4-D5 & $103( \pm 3)$ \\
\hline
\end{tabular}

damage ratio $\left(D_{\mathrm{R}}\right)$ as the total decrease of the building value due to seismic effects; this parameter, multiplied by the cost of construction, represents the total amount of economic loss. In the following formula, assuming a cost of construction that equals $1, D_{\mathrm{R}}$ is calculated as the sum of the average $\mathrm{Cr}$ values reported in Table 4 multiplied by the extension of each damage level:

$$
\begin{aligned}
D_{\mathrm{R}}= & 5 \% * D_{1}+20 \% * D_{2}+45 \% * D_{3}+103 \% *\left(D_{4}\right. \\
& \left.+D_{5}\right)
\end{aligned}
$$

Summing up, the building damage scenario was calculated at the municipal level. The total amount of building damage in a municipality is represented by $D_{\mathrm{R}}$. The damage ratio distribution is shown in Fig. 5a. As expected, the greatest values of the damage ratio match with the most severely shocked epicentral area, or alternatively, the most densely populated municipalities.
The application of this procedure to a real scenario is rather difficult, because the construction cost is rarely available as it is greatly influenced by many factors such as structural type, construction quality, building materials, and the location of the house in the urban context. Usually damages are combined with regionally calibrated parameters to calculate the direct economic losses. As an example, the construction cost per square meter of each building type is dependent on the average rental rate and on the annual gross sales.

This study quantifies loss as a percentage of the building value that corresponds to the property value on the market provided by OMI, and not to the cost of construction. The adoption of a market value, including both direct and part of indirect costs, should lead to a higher estimated monetary loss value because it considers multiple factors.

For each municipality a minimum and a maximum OMI value are available and an average value was adopted to perform the economic analysis. The distribution of these average municipal real estate values is shown in Fig. 5b. The highest OMI values correspond to the city of Modena and to other smaller municipalities in the southern part of the study area, whereas the lowest values are found in the rural territory near the Po River in Mantova Province, where buildings are poorly built and therefore highly vulnerable to seismic events (Fig. 3).

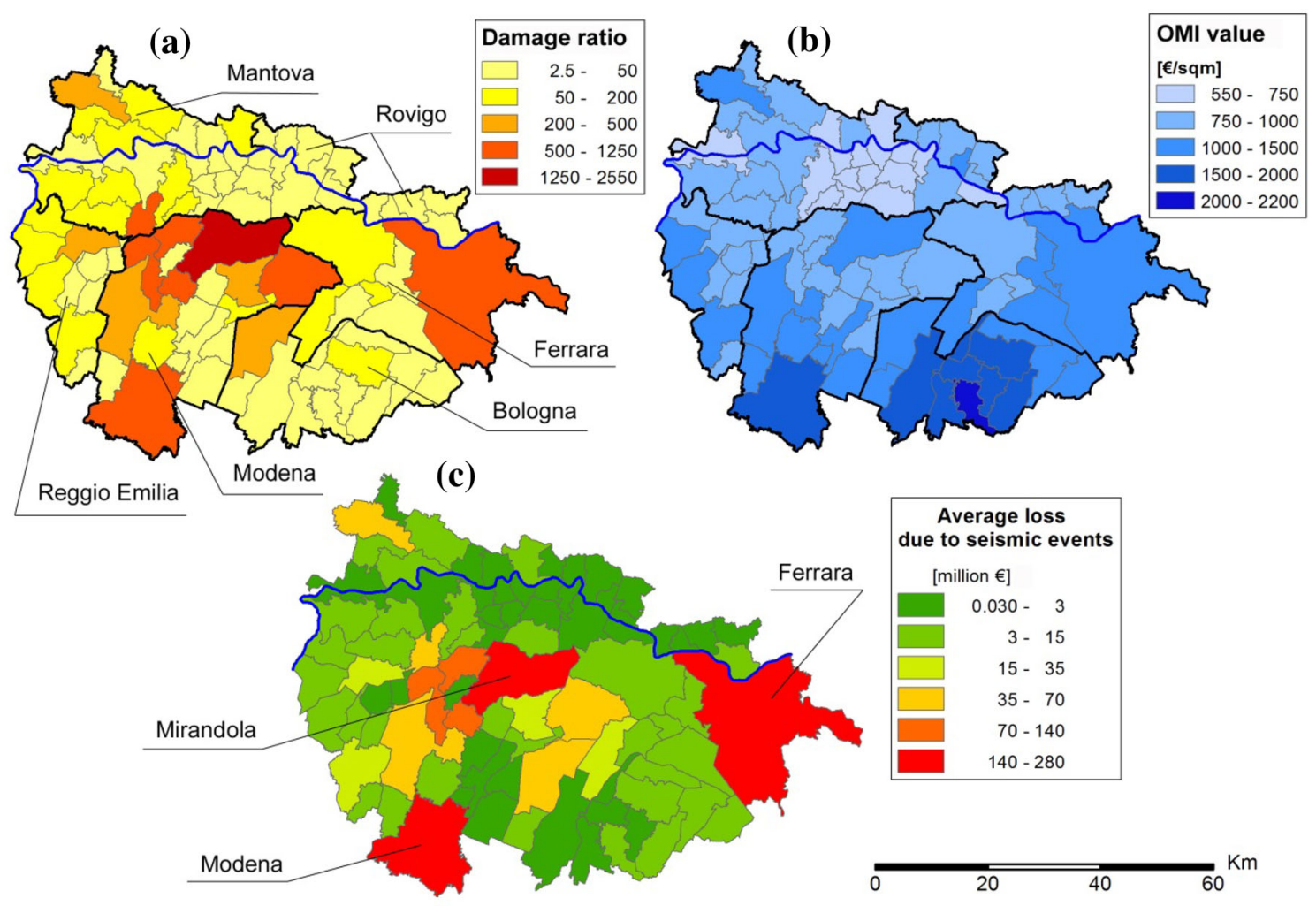

Fig. 5 Distribution of the features related to the economic loss assessment. a Distribution of damage ratio $D_{R}$. b The average municipal OMI value. Darker lines represent the provincial areas. c The average loss for each municipality. The blue line represents the Po River 
Table 6 Parameters and results of sensitivity analysis in the loss assessment

(a) Different combinations of the minimum (-), average, and maximum (+) values of the parameters cost ratio and OMI data considered in the sensitivity analysis

\begin{tabular}{|c|c|c|c|}
\hline & $\mathrm{Cr}_{\min }$ & $\mathrm{Cr}_{\text {ave }}$ & $\mathrm{Cr}_{\max }$ \\
\hline $\mathrm{OMI}_{\min }$ & Loss min & Loss $\mathrm{OMI}^{-}$ & Loss $\mathrm{Cr}^{+} \mathrm{OMI}^{-}$ \\
\hline $\mathrm{OMI}_{\mathrm{ave}}$ & Loss $\mathrm{Cr}^{-} \mathrm{OMI}$ & Loss & Loss $\mathrm{Cr}^{+} \mathrm{OMI}$ \\
\hline $\mathrm{OMI}_{\max }$ & Loss $\mathrm{Cr}^{-} \mathrm{OMI}^{+}$ & Loss $\mathrm{OMI}^{+}$ & Loss max \\
\hline
\end{tabular}

(b) Overall economic losses of some tested cases. The results (in million Euro) are provided for each province of the study area

\begin{tabular}{|l|l|l|l|l|l|}
\hline Province & Loss min & Loss OMI & Loss & Loss OMI & Loss max \\
\hline Mantova & 108.5 & 151.1 & 174.1 & 197.0 & 252.7 \\
\hline Rovigo & 12.2 & 18.5 & 21.6 & 24.7 & 33.1 \\
\hline Reggio & 56.9 & 81.4 & 91.8 & 102.3 & 133.1 \\
\hline Modena & 527.0 & 681.8 & 795.1 & 908.5 & 1114.7 \\
\hline Bologna & 67.7 & 96.4 & 106.2 & 116.0 & 150.5 \\
\hline Ferrara & 124.4 & 186.8 & 212.0 & 237.2 & 316.4 \\
\hline Total losses & 896.8 & 1215.9 & 1400.8 & 1585.7 & 2000.4 \\
\hline
\end{tabular}

The overall loss is calculated by multiplying $D_{\mathrm{R}}$ and the average OMI market value for each municipality, adopting the minimum, maximum, and average values of both parameters and testing all the possible combinations (Table 6a). As reference value, the average municipal loss (orange area in Table 6) is shown in Fig. 5c.

The resulting average monetary losses estimated in the study area is just higher than 1400 million Euro. At the provincial level, the most significant loss occurred in Modena Province with more than 795 million Euro, followed by the Ferrara and Mantova Provinces with more than 212 and 175 million Euro, and finally, the provinces of Bologna, Reggio Emilia, and Rovigo with 106, 92, and 21 million Euro, respectively. The town that has faced the greatest loss is Mirandola, with an estimated loss of approximately 245 million Euro. Modena and Ferrara, rather far from the epicentral area and thus exposed to a moderate level of shaking, suffered high loss (162 and 148 million Euro) probably due to the large number of damaged buildings combined with their high market value.
A sensitivity analysis was carried out in order to check the influence of the variability of the considered parameters on the final loss. Table 6 reports: (a) the scheme of the analysis and (b) the related loss. By keeping a steady average value for $\mathrm{Cr}$ and varying the municipal OMI market value, the overall loss ranges between $\pm 13.2 \%$ (light yellow areas) compared to the reference average loss (orange area). In contrast, with a steady average OMI value and a variable $\mathrm{Cr}$, the overall loss ranges between $\pm 26.2 \%$ (light yellow areas), which highlights this parameter as the most sensitive for the model. By varying both $\mathrm{Cr}$ and $\mathrm{OMI}$ values, the final extreme loss ranges from - $36 \%$ up to $+43 \%$ (dark yellow areas). Some quantifications of loss are given in Table $6 \mathrm{~b}$ for each province.

The results emphasize that, by varying the OMI values (Loss $\mathrm{OMI}^{-}$and Loss $\mathrm{OMI}^{+}$), Rovigo Province records a maximum variability $( \pm 14 \%)$ and, conversely, a minimum value is recorded for Bologna Province $( \pm 9 \%)$. Accounting for the extreme values of both $\mathrm{Cr}$ and OMI parameters, the Loss min and Loss max have the maximum 
variability for Rovigo Province $(-43$ to $+53 \%)$, whereas the lowest difference occurs in Bologna Province $(-36$ to $+42 \%)$. These loss estimates are related to direct loss of residential built-up areas only, and do not account for such induced losses as relocation, unrealized losses, and the loss of income and lease (Whitman et al. 1997), neither is damage that occurred to infrastructures, facilities, and productive activities taken into account.

\section{Conclusion}

This study presents a viable procedure for assessing the economic loss suffered by the municipalities in a welldeveloped urban area hit by a seismic event of moderate magnitude by using freely available data as input. The 2012 Emilia earthquake in Italy is well suited as a representative case study for an economic loss assessment in the most frequent case of moderate hazard and high exposure area. The analysis, performed at the subregional scale, combines the national census data provided by ISTAT with macroseismic intensity surveyed after the events. The study focuses on the economic quantification of the residential building damage caused by an earthquake, and adopts the housing market value provided by OMI as a reliable economic indicator, instead of the cost of construction, which is commonly used, but is difficult to quantify.

Initially implemented at a detailed scale, the loss assessment procedure was then developed at a municipal scale through the introduction of several critical assumptions, such as that a set of intensity values rounded off at municipal scale and an updated building vulnerability analysis based on revised ISTAT data processing. The proposed procedure can easily be applied to develop scenarios of earthquake loss in other areas of Italy by taking advantage of publicly available and reliable input data, which is constantly revised by public authorities.

It is not easily possible to validate our analysis, nor to perform a comparison between the presented loss assessments, related to residential building only, with the spending forecast estimated by local authorities responsible for reconstruction, which also considers damage to infrastructure and nonresidential structures (Centro studi 2014). Estimates of the overall economic costs of an earthquake consider a wide range of variables in addition to the losses related to damaged residential buildings, such as the funding costs for repair or replacement of damaged public buildings, removal, disposal, and replacement costs of damaged infrastructure (roads, railways, water supply systems, sewerage collection and treatment systems, natural gas pipelines, and solid waste collection, treatment, and disposal systems), damaged historical and artistic heritage, and destructive impacts and activity interruptions inflicted on other productive activities (service industries, agriculture, and factories). The estimated cost to residential buildings provided in this study, which ranged from 900 million to a maximum of 2000 million Euro, reasonably represents $10-15 \%$ of the total amount provided by other, more comprehensive estimates (Centro studi 2014; Mucciarelli and Liberatore 2014).

Further validation procedures might be possible by considering data released by the regional administrations that report their loss estimates and investments in the affected area. For instance, the Emilia-Romagna Region has already granted about 2000 million Euro intended for the reconstruction of residential buildings and commercial areas (Regione Emilia Romagna 2017). This estimate refers to the situation as of February 2017, and it is updated monthly as the reconstruction process is still on going.

An additional source of data for a future improvement of this work may come from detailed surveys performed after each earthquake by the Italian Protezione Civile (Civil Protection) department, covering the extent to which residential buildings have incurred damage (Masi et al. 2017). Although the main purpose of these surveys is to define the level of usability of each damaged building, these data can also be used to verify the reliability of the damage scenario based on macroseismic intensity data, as soon as the collected data are made public.

Acknowledgements This work was carried out within the framework of the project "The Economic Assessment of Natural Disasters in Italy" (La valutazione economica dei disastri naturali in Italia, in Italian) funded by Fondazione Generali from 2013 to 2017. We thank the two anonymous reviewers for their suggestions that improved the paper.

Open Access This article is distributed under the terms of the Creative Commons Attribution 4.0 International License (http://crea tivecommons.org/licenses/by/4.0/), which permits unrestricted use, distribution, and reproduction in any medium, provided you give appropriate credit to the original author(s) and the source, provide a link to the Creative Commons license, and indicate if changes were made.

\section{References}

ANIA (Associazione Nazionale fra le Imprese Assicuratrici/National Association of Insurers Companies) and Guy Capenter groups. 2011. Damage due to seismic and flood events on Italian housing: Quantitative study and possibile insurance schemes (Danni da eventi sismici e alluvionali al patrimonio abitativo italiano: studio quantitativo e possibili schemi assicurativi). Report. http://www.ania.it/export/sites/default/it/pubblicazioni/ monografie-e-interventi/Danni/Danni-da-eventi-sismici-e-allu vionali.pdf. Accessed 7 Sept 2017 (in Italian). 
ATC (Applied Technology Council). 1985. Earthquake damage evaluation. Data for California. Report No. ATC-13. Redwood City, CA, USA.

Bal, I.E., H. Crowley, R. Pinho, and F.G. Gulay. 2008. Detailed assessment of structural characteristics of Turkish RC building stock for loss assessment models. Soil Dynamics and Earthquake Engineering 28(10/11): 914-932.

Bater, C.W., and N.C. Coops. 2009. Evaluating error associated with LiDAR-derived DEM interpolation. Computers \& Geosciences 35(2): 289-300.

Benedetti, D., and V. Petrini. 1984. On seismic vulnerability of masonry buildings: Proposal of an evaluation procedure. L'industria delle Costruzioni 18: 66-78 (in Italian).

Bernardini, A., S. Giovinazzi, S. Lagomarsino, and S. Parodi. 2007. The vulnerability assessment of current buildings by a macroseismic approach derived from the EMS-98 scale. The $3 \mathrm{rd}$ Congreso National de Ingeniería Sismíca, 8-11 May 2007, Girona. Asociación Española de Ingeniería Sísmica, 704-718.

Bernardini, A., L. Salmaso, and A. Solari. 2008. Statistical evaluation of vulnerability and expected seismic damage of residential buildings in the Veneto-Friuli area (NE Italy). Bollettino di Geofisica Teorica e Applicata 49(3-4): 427-446.

Bevere, L., O. Kuebler, and C. Honegger. 2015. The natural catastrophe protection gap in Italy: Time for action. Swiss Re Ltd. http://www.swissre.com/library/The_natural_catastrophe_ protection_gap_in_Italy_time_for_action.html. Accessed 7 Sept 2017.

Burrato, P., P. Vannoli, U. Fracassi, R. Basili, and G. Valensise. 2012. Is blind faulting truly invisible? Tectonic-controlled drainage evolution in the epicentral area of the May 2012, EmiliaRomagna earthquake sequence (northern Italy). Annals of Geophysics 55(4): 525-531.

Castelli, V., F. Bernardini, R. Camassi, C.H. Caracciolo, E. Ercolani, and L. Postpischl. 2012. Looking for missing earthquakes traces in the Ferrara-Modena plain: An update on historical seismicity. Annals of Geophysics 55(4): 519-524.

Centro studi. 2014. The earthquake costs in Italy (I costi dei terremoti in Italia). Roma: Consiglio nazionale ingegneri. http://cache.b. centrostudicni.it/images/pubblicazioni/ricerche/cr470_costi_ter remoto_59a5d.pdf. Accessed 7 Sept 2017 (in Italian).

Chay, K.Y., and M. Greenstone. 2005. Does air quality matter? Evidence from the housing market. Journal of Political Economy 113(2): 376-424.

Cipollotti, G.B. 2013. Criteria for the cost assessment in the real estate appraisal (Il criterio del costo nella stima immobiliare). Aestimum 62: 111-127 (in Italian).

Davis, L.W. 2011. The effect of power plants on local housing values and rents. Review of Economics and Statistics 93(4): 1391-1402.

Erdik, M., K. Sesetyan, M. Betul Demircioglu, U. Hancilar, and C. Zulfikar. 2010. Rapid earthquake loss assessment after damaging earthquakes. In Earthquake engineering in Europe, vol. 17, ed. M. Garevski, and A. Ansal, 523-547. Dordrecht: Springer.

FEMA (Federal Emergency Management Agency). 2003. Multihazard loss estimation methodology, earthquake model HAZUSMHMR1, advanced engineering building module, technical and user's manual. Washington, DC: FEMA.

Galli, P., S. Castenetto, and E. Peronace. 2012. The MCS macroseismic survey of the Emilia 2012 earthquakes. Annals of Geophysics 55(4): 663-672.

Giovinazzi, S., and S. Lagomarsino. 2004. Exposure and vulnerability of buildings in the Imperia province (Esposizione e vulnerabilità del costruito in provincia di Imperia). Italian meeting "Rischio sismico, territorio e centri storici". Sanremo (IM), 2-3 July 2004, ed. S. Lagomarsino, and P. Ugolini, 321-332. Milan: FrancoAngeli (in Italian).
Glaeser, E.L., and J. Gyourko. 2005. Urban decline and durable housing. Journal of Political Economy 113(2): 345-375.

Glaeser, E.L., J. Gyourko, and R. Saks. 2005. Why have housing prices gone up? No. w11129. National Bureau of Economic Research. http://www.nber.org/papers/w11129. Accessed 7 Sept 2017.

Grünthal, G. (ed.). 1998. European macroseismic scale 1998 (EMS98). European Seismological Commission, Sub Commission on Engineering Seismology, Working Group Macroseismic Scales. Conseil de l'Europe, Cahiers du Centre Européen de Géodynamique et de Séismologie 15. Luxembourg.

Gruppo di Lavoro MPS. 2004. Seismic hazard map of the Decree 3274 of 20 March 2003 (Redazione della mappa di pericolosità sismica prevista dall'Ordinanza PCM 3274 del 20 marzo 2003). Rapporto Conclusivo per il Dipartimento della Protezione Civile, INGV, Milano-Roma. http://zonesismiche.mi.ingv.it. Accessed 7 Sept 2017 (in Italian).

ISTAT (Istituto Nazionale di Statistica/National Institute of Statistics). 1991. The 13th general census on population-Data on population, housing characteristics and economical variables (Censimento generale della popolazione-Dati sulle caratteristiche strutturale della popolazione, delle abitazioni e variabili economiche). http://www.istat.it/it/archivio/104317. Accessed 13 Sept 2017 (in Italian).

Lagomarsino, S., and S. Giovinazzi. 2006. Macroseismic and mechanical models for the vulnerability and damage assessment of current buildings. Bulletin of Earthquake Engineering 4(4): 415-443.

Lantada, N., J. Irizarry, A.H. Barbat, X. Goula, A. Roca, T. Susagna, and L.G. Pujades. 2010. Seismic hazard and risk scenarios for Barcelona, Spain, using the Risk-UE vulnerability index method. Bulletin of Earthquake Engineering 8(2): 201-229.

Liberatore, L., L. Sorrentino, D. Liberatore, and L.D. Decanini. 2013. Failure of industrial structures induced by the Emilia (Italy) 2012 earthquakes. Engineering Failure Analysis 34: 629-647.

Masi, A., G. Santarsiero, A. Digrisolo, L. Chiauzzi, and V. Manfredi. 2017. Procedures and experiences in the post-earthquake usability evaluation of ordinary buildings. Bollettino di Geofisica Teorica e Applicata 52(2): 119-220.

Meroni, F., V. Pessina, and A. Bernardini. 2008a. Damage risk and scenarios in the Veneto-Friuli area. Bollettino di Geofisica Teorica e Applicata 49(3-4): 485-503.

Meroni, F., V. Pessina, A. Bernardini, M. Valluzzi, and D. D'Ayala. 2008b. Damage scenarios in the Vittorio Veneto town center. Bollettino di Geofisica Teorica e Applicata 49(3-4): 505-512.

Meroni, F., V. Pessina, T. Squarcina, M. Locali, R. Zoboli, and M. Modica. 2016. The economic assessment of seismic damage: An example for the 2012 event in northern Italy. International Conference on Urban Risk, Lisbon, 30 June-2 July 2016, 323-330.

Meroni, F., V. Petrini, and G. Zonno. 2000. National distribution of the average municipal vulnerability (Distribuzione nazionale della vulnerabilità media comunale). In La vulnerabilità degli edifici, ed. A. Bernardini, 105-131. Roma: CNR-GNDT (in Italian).

Modica, M., R. Zoboli, F. Meroni, V. Pessina, T. Squarcina, and M. Locati. 2016. Housing market response to 2012 northern Italy earthquake: The role of house quality and changing risk perception. SEEDS, Sustainability Environmental Economics and Dynamics Studies. Working paper 4: 1-26. http://econpa pers.repec.org/RePEc:srt:wpaper:0416. Accessed 7 Sept 2017.

Montealegre, A.L., M.T. Teresa Lamelas, and J. De la Riva. 2015. Interpolation routines assessment in ALS-derived digital elevation models for forestry applications. Remote Sensing 7(7): $8631-8654$. 
Mouroux, P. 2003. RISK-UE-An advanced approach to earthquake risk scenarios with applications to different European towns. Final report. Brussels: European Commission.

Mouroux, P., and B. Le Brun. 2006. Risk-Ue project: An advanced approach to earthquake risk scenarios with application to different European towns. In Assessing and managing earthquake risk, ed. C.S. Oliveira, A. Roca, and X. Goula, 479-508. Vol. 2. Berlin: Springer.

Mucciarelli, M., and D. Liberatore. 2014. Guest editorial: The Emilia 2012 earthquakes, Italy. Bulletin of Earthquake Engineering 12(5): 2111-2116.

Murdoch, J.C., H. Singh, and M. Thayer. 1993. The impact of natural hazards on housing values: The Loma Prieta earthquake. Journal of the American Real Estate and Urban Economics Association 21(2): 167-184.

Musson, R.M.W., G. Grünthal, and M. Stucchi. 2010. The comparison of macroseismic intensity scales. Journal of Seismology 14(2): 413-428.

Naoi, M., M. Seko, and K. Sumita. 2009. Earthquake risk and housing prices in Japan: Evidence before and after massive earthquakes. Regional Science and Urban Economics 39(6): 658-669.

Norme Tecniche per le Costruzioni. 2008. Technical standards for construction (Norme tecniche per le costruzioni). Decree of the Minister of the Infrastructures, 14 January 2008, Italian Official Gazette n. 29 of 4 February 2008. http://www.gazzettaufficiale. it/eli/id/2008/02/04/08A00368/sg. Accessed 7 Sept 2017 (in Italian).

OPCM 3274 (Ordinanza del Presidente del Consiglio dei Ministri 3274). 2003. General criteria for the seismic classification of the national territory and technical standards (Primi elementi in materia di criteri generali per la classificazione del territorio nazionale e di normative tecniche). G.U. n. 105 del 08/05/2003. http://zonesismiche.mi.ingv.it/documenti/gazzetta.pdf. Accessed 7 Sept 2017 (in Italian).

Osservatorio del Mercato Immobiliare. 2009. Agency of the real estate market database manual (Manuale della banca dati dell'osservatorio del mercato immobiliare). Version 1.3. http:// www.agenziaentrate.gov.it/wps/content/Nsilib/Nsi/Documenta zione/omi/Manuali+e+guide/. Accessed 2015 (in Italian).

Pessina, V., F. Meroni, T. Squarcina, M. Locati, A. Tertulliani, and I. Leschiutta. 2014. Validation of macroseismic models for the assessment of damage (Validazione di modelli macrosismici per la stima del danneggiamento). The XXXIII Italian Convention Gruppo Nazionale di Geofisica della Terra Solida. Bologna, 2527 November 2014, ed. D. Slejko et al., 2: 457-463. http:// www3.ogs.trieste.it/gngts/files/2014/S23/Riassunti/Pessina.pdf. Accessed 7 Sept 2017 (in Italian).

Regione Emila Romagna. 2017. Earthquake, the reconstruction (Terremoto, la ricostruzione). http://www.regione.emiliaromagna.it/terremoto (in Italian).

Riedel, I., P. Gueguen, M. Dalla Mura, E. Pathier, T. Leduc, and J. Chanussot. 2015. Seismic vulnerability assessment of urban environments in moderate-to-low seismic hazard regions using association rule learning and support vector machine methods. Natural Hazards 76(2): 1111-1141.

Riedel, I., P. Gueguen, F. Dunand, and S. Cottaz. 2014. Macroscale vulnerability assessment of cities using association rule learning. Seismological Research Letters 85(2): 295-305.

Roca, A., X. Goula, T. Susagna, J. Chavez, M. Gonzalez, and E. Reinoso. 2006. A simplified method for vulnerability assessment of dwelling buildings and estimation of damage scenarios in Catalonia. Bulletin of Earthquake Engineering 4(2): 141-158.

Rovida, A., M. Locati, R. Camassi, B. Lolli, and P. Gasperini. 2016. CPTI15, the 2015 version of the parametric catalogue of Italian earthquakes. Istituto Nazionale di Geofisica e Vulcanologia. http://doi.org/10.6092/INGV.IT-CPTI15.

Sambridge, M., J. Braun, and H. McQueen. 1995. Geophysical parametrization and interpolation of irregular data using natural neighbours. Geophysical Journal International 122(3): 837-857.

Scognamiglio, L., L. Margheriti, F.M. Mele, E. Tinti, A. Bono, P. De Gori, V. Lauciani, F.P. Lucente, A.G. Mandiello, C. Marcocci, S. Mazza, S. Pintore, and M. Quintiliani. 2012. The 2012 Pianura Padana Emilianan seismic sequence: Location, moment tensors and magnitudes. Annals of Geophysics 55(4): 549-559.

Sieberg, A. 1930. The earthquake geology (Geologie der Erdbeben). Handbuch der Geophysik 2(4): 550-555 (in German).

Spence, R. 2007. Earthquake disaster scenario prediction and loss modelling for urban areas. LessLoss report 7. http://elsa.jrc.ec. europa.eu/events.php?id=4. Accessed 7 Sept 2017.

Syner-G Project. 2012. Systemic seismic vulnerability and risk analysis for buildings, lifeline networks and infrastructures safety gain. European research project funded by FP7. http:// www.vce.at/SYNER-G/. Accessed 7 Sept 2017.

Tertulliani, A., L. Arcoraci, M. Berardi, F. Bernardini, B. Brizuela, C. Castellano, S. Del Mese, E. Ercolani, L. Graziani, A. Maramai, A. Rossi, M. Sbarra, and M. Vecchi. 2012. The Emilia 2012 sequence: A macroseismic survey. Annals of Geophysics 55(4): 679-687.

UPStrat-MAFA (Urban Prevention Strategies using MAcroseismic and FAult Sources). 2012. Urban disaster prevention strategies using macroseismic fields and fault sources. EC project number 230301/2011/613486/SUB/A5), DG ECHO Unit A5. http:// upstrat-mafa.ov.ingv.it/UPStrat/. Accessed 7 Sept 2017.

Whitman, R.V., T. Anagnos, C.A. Kirker, H.J. Lagorio, R.S. Lawson, and P. Schneider. 1997. Development of a national earthquake loss estimation methodology. Earthquake Spectra 13(4): 643-661.

Zonno, G., C.S. Oliveira, M.A. Ferreira, G. Musacchio, F. Meroni, F. Mota-de-Sá, and F. Neves. 2010. Assessing seismic damage through stochastic simulation of ground shaking: The case of the 1998 Faial earthquake (Azores Islands). Surveys in Geophysics 31(3): 361-381. 